\title{
The Effects of Acute Hydrogen Sulfide Poisoning on Cytochrome P450 Isoforms Activity in Rats
}

\author{
Xianqin Wang, ${ }^{1}$ Mengchun Chen, ${ }^{1}$ Xinxin Chen, ${ }^{1}$ Jianshe Ma, ${ }^{1}$ Congcong Wen, ${ }^{1}$ \\ Jianchun Pan, ${ }^{1}$ Lufeng $\mathrm{Hu}^{2}{ }^{2}$ and Guanyang Lin ${ }^{2}$ \\ ${ }^{1}$ Analytical and Testing Center, Wenzhou Medical University, Wenzhou 325035, China \\ ${ }^{2}$ The First Affiliated Hospital, Wenzhou Medical University, Wenzhou 325000, China \\ Correspondence should be addressed to Guanyang Lin; guanyanglinwzmc@gmail.com
}

Received 15 October 2013; Accepted 20 February 2014; Published 26 March 2014

Academic Editor: Eva Widerstrom-Noga

Copyright (C) 2014 Xianqin Wang et al. This is an open access article distributed under the Creative Commons Attribution License, which permits unrestricted use, distribution, and reproduction in any medium, provided the original work is properly cited.

Hydrogen sulfide $\left(\mathrm{H}_{2} \mathrm{~S}\right)$ is the second leading cause of toxin related death (after carbon monoxide) in the workplace. $\mathrm{H}_{2} \mathrm{~S}$ is absorbed by the upper respiratory tract mucosa, and it causes histotoxic hypoxemia and respiratory depression. Cocktail method was used to evaluate the influences of acute $\mathrm{H}_{2}$ S poisoning on the activities of cytochrome P450 isoforms CYP2B6, CYP2D6, CYP3A4, CYP1A2, CYP2C19, and CYP2C9, which were reflected by the changes of pharmacokinetic parameters of six specific probe drugs, bupropion, metoprolol, midazolam, phenacetin, omeprazole, and tolbutamide, respectively. The experimental rats were randomly divided into two groups, control group and acute $\mathrm{H}_{2} \mathrm{~S}$ poisoning group (inhaling $300 \mathrm{ppm}$ for $2 \mathrm{~h}$ ). The mixture of six probes was given to rats by oral administration and the blood samples were obtained at a series of time points through the caudal vein. The concentrations of probe drugs in rat plasma were measured by LC-MS. The results for acute $\mathrm{H}_{2} \mathrm{~S}$ poisoning and control groups were as follows: there was a statistically significant difference in the AUC and $C_{\max }$ for bupropion, metoprolol, phenacetin, and tolbutamide, while there was no statistical pharmacokinetic difference for midazolam and omeprazole. Acute $\mathrm{H}_{2} \mathrm{~S}$ poisoning could inhibit the activity of CYP2B6, CYP2D6, CYP1A2, and CYP2C9 in rats.

\section{Introduction}

Hydrogen sulfide $\left(\mathrm{H}_{2} \mathrm{~S}\right)$ is one of the major toxic gases $[1]$; it is the second leading cause of toxin related death (after carbon monoxide) in the workplace [2]. $\mathrm{H}_{2} \mathrm{~S}$ has a specific gravity of 1.19 and the characteristic odor of rotten eggs [3]. $\mathrm{H}_{2} \mathrm{~S}$ is poisonous, and accidents may occur on exposure to natural gas, volcanic gas, and industrial waste [4]. Accidents have been reported in chemical processing plants $[5,6]$ and sewage disposal facilities [7-10] and with the ingestion of sulfur products $[11,12]$. Acute toxicity of $\mathrm{H}_{2} \mathrm{~S}$ involves mainly the central nervous system and lungs [13]. It may cause variable neurologic symptoms such as dizziness, headache, poor coordination, and brief loss of consciousness after exposure to high concentrations of $\mathrm{H}_{2} \mathrm{~S}$. If exposure is transient, recovery is usually complete and rapid. However, in some instances, prolonged or severe exposure leads to a fatal outcome or permanent sequelae $[14,15]$.
Cytochrome $\mathrm{P} 450$ s are thiolate-ligated heme enzymes that use dioxygen and the formal equivalents of molecular hydrogen $(2 \mathrm{H}+$ and $2 \mathrm{e}-)$ to functionalize a wide range of biologically active compounds $[16,17]$. Cytochrome P450 (CYP) is the most important drug metabolizing enzyme family contributing to the metabolism of the majority of drugs in humans [18-20]. CYP450 enzymes reduce or alter the pharmacodynamic activity of many drugs and are involved in $\sim 80 \%$ of oxidative drug metabolism and $50 \%$ of elimination of commonly used drugs [21]. The main isoenzymes are CYP1A2, 2C9, 2D6, and 3A4; and $20-25 \%$ of the population, depending on ethnic background, has genetic differences in drug metabolism by CYP450 [22]. In order to assess various individual CYP450 activities, probe drugs have been widely used in many clinical investigations in the field of drug metabolism and pharmacogenetics [23-25]. Probe drug is one kind of compound specially catalyzed by CYP isoforms, and the activities of CYP isoforms can be reflected by the 
metabolic rate of probe drug. As several CYP isoforms are involved in drug metabolism, the cocktail approach was developed.

At present, the study of $\mathrm{H}_{2} \mathrm{~S}$ toxicology mainly focuses on the central nervous system and cardiovascular system [2632]. To our knowledge, there are few reports about the hepatic toxicity of $\mathrm{H}_{2} \mathrm{~S}$. In this paper, cocktail probe drugs approach is used to evaluate the induction or inhibition effects of $\mathrm{H}_{2} \mathrm{~S}$ on the activities of rats CYP450 isoforms such as CYP2B6, CYP2D6, CYP3A4, CYP1A2, CYP2C19, and CYP2C9, which are reflected by the changes of pharmacokinetic parameters from 6 specific probe drugs, bupropion, metoprolol, midazolam, phenacetin, omeprazole, and tolbutamide, and then to provide a guidance for rational clinical oral administration after acute $\mathrm{H}_{2} \mathrm{~S}$ poisoning.

\section{Material and Methods}

2.1. Chemicals and Reagents. Bupropion, metoprolol, midazolam, phenacetin, omeprazole, tolbutamide (all >98\%), and the internal standard carbamazepine (IS) were purchased from Sigma-Aldrich Company (St. Louis, USA). HPLC grade acetonitrile and methanol were from Merck Company (Darmstadt, Germany). All other chemicals were of analytical grade. Ultrapure water (resistance $>18 \mathrm{~m} \Omega$ ) was prepared by a Millipore Milli-Q purification system (Bedford, USA).

2.2. Animals. Male Sprague-Dawley rats $(250 \pm 20 \mathrm{~g})$ were obtained from Shanghai SLAC Laboratory Animal Co., Ltd. The animal license number was SCXK (Shanghai) 2012-0005. All twenty rats were housed at Wenzhou Medical University Laboratory Animal Research Center. Animals were housed under controlled conditions $\left(22^{\circ} \mathrm{C}\right)$ with a natural light-dark cycle. All experimental procedures were conducted according to the Institutional Animal Care guidelines and approved ethically by the Administration Committee of Experimental Animals, Laboratory Animal Center of Wenzhou Medical University.

2.3. Instrumentation and Conditions. Bruker Esquire HCT mass spectrometer (Bruker Technologies, Bremen, Germany) equipped with a 1200 Series liquid chromatograph (Agilent Technologies, Waldbronn, Germany) and controlled by ChemStation software (Version B.01.03 [204], Agilent Technologies, Waldbronn, Germany) was used.

Chromatographic separation was achieved on a $150 \mathrm{~mm} \times$ $2.1 \mathrm{~mm}, 5 \mu \mathrm{m}$ particle, Agilent Zorbax SB-C18 column at $30^{\circ} \mathrm{C}$. A gradient elution programme was conducted for chromatographic separation with mobile phase A ( $0.1 \%$ formic acid in water) and mobile phase $\mathrm{B}$ (acetonitrile) as follows: 0-4.0 min (10-80\% B), 4.0-8.0 min (80-80\% B), 8.0-9.0 min $(80-10 \% \mathrm{~B})$, and $9.0-13.0 \mathrm{~min}(10-10 \% \mathrm{~B})$. The flow rate was $0.4 \mathrm{~mL} / \mathrm{min}$.

The quantification was performed by the peak area method. The determination of target ions was performed in selective ion monitoring mode $(\mathrm{m} / z 240$ for bupropion, $\mathrm{m} / \mathrm{z} 268$ for metoprolol, $\mathrm{m} / \mathrm{z} 326$ for midazolam, $\mathrm{m} / \mathrm{z}$ 180 for phenacetin, $m / z 198$ for omeprazole, $m / z 271$ for tolbutamide, and $m / z 237$ for IS) and positive ion electrospray ionization interface. Drying gas flow was set to $7 \mathrm{~L} / \mathrm{min}$ and temperature to $350^{\circ} \mathrm{C}$. Nebuliser pressure and capillary voltage of the system were adjusted to 25 psi and $3,500 \mathrm{~V}$, respectively.

2.4. Preparation of Standard Solutions. Stock solutions of $1.0 \mathrm{mg} / \mathrm{mL}$ for each of bupropion, metoprolol, midazolam, phenacetin, omeprazole, tolbutamide, and IS were prepared in methanol. The working standard solutions of each analyte were prepared by serial dilution of the stock solution with methanol. All of the solutions were stored at $4^{\circ} \mathrm{C}$ and brought to room temperature before use.

The calibration standards were prepared by spiking blank rat plasma with appropriate amounts of bupropion, metoprolol, midazolam, phenacetin, omeprazole, and tolbutamide. Calibration plots of each probe drug were constructed in the range $10-2000 \mathrm{ng} / \mathrm{mL}$ for plasma $(10,20,50,100,200$, 500,1000 , and $2000 \mathrm{ng} / \mathrm{mL}$ ). Quality-control (QC) samples were prepared by the same way as the calibration standards, with three different plasma concentrations (20, 200, and $1600 \mathrm{ng} / \mathrm{mL}$ ). The analytical standards and QC samples were stored at $-20^{\circ} \mathrm{C}$.

2.5. Pharmacokinetic Study. Twenty male Sprague-Dawley rats $(250 \pm 20 \mathrm{~g})$ were randomly divided to control group and acute $\mathrm{H}_{2} \mathrm{~S}$ poisoning group $(n=8)$; the rats were placed in triad infected ark which was with the $\mathrm{H}_{2} \mathrm{~S}$ detector and passed into a certain concentration of $\mathrm{H}_{2} \mathrm{~S}$ gases to create a model of acute $\mathrm{H}_{2} \mathrm{~S}$ poisoning. The acute $\mathrm{H}_{2} \mathrm{~S}$ poisoning group rats were exposed to $300 \mathrm{ppm} \mathrm{H}_{2} \mathrm{~S}$ for $2 \mathrm{~h}$. Control animals were maintained under similar conditions, but without the $\mathrm{H}_{2} \mathrm{~S}$ exposure. Rats were allowed to eat and drink ad libitum except during the $2 \mathrm{~h}$ exposure.

After completing the modeling, the acute $\mathrm{H}_{2} \mathrm{~S}$ poisoning and control rats were given the mixed six probe drugs with oral administration. The administration dose of the probe drugs bupropion, metoprolol, midazolam, phenacetin, omeprazole, and tolbutamide were $10 \mathrm{mg} / \mathrm{kg}, 10 \mathrm{mg} / \mathrm{kg}$, $10 \mathrm{mg} / \mathrm{kg}, 10 \mathrm{mg} / \mathrm{kg}, 10 \mathrm{mg} / \mathrm{kg}$, and $1 \mathrm{mg} / \mathrm{kg}$, respectively.

Blood samples $(0.3 \mathrm{~mL})$ were collected from the tail vein into heparinized $1.5 \mathrm{~mL}$ polythene tubes at 5,15 , and $30 \mathrm{~min}$ and $1,1.5,2,3,4,5,6,8,12,24$, and $48 \mathrm{~h}$ after oral administration of probe drugs. The samples were immediately centrifuged at $8000 \mathrm{r} / \mathrm{min}$ for $5 \mathrm{~min}$, and $100 \mu \mathrm{L}$ plasma was obtained for each sample.

The plasma samples were extracted and measured by LCMS. In a $1.5 \mathrm{~mL}$ centrifuge tube, an aliquot of $10 \mu \mathrm{L}$ of the internal standard working solution $(2.0 \mu \mathrm{g} / \mathrm{mL})$ was added to $0.1 \mathrm{~mL}$ of collected plasma sample followed by the addition of $0.2 \mathrm{~mL}$ of acetonitrile-methanol (v/v, 9:1). After the tube was vortex-mixed for $1.0 \mathrm{~min}$, the sample was centrifuged at 15000 rmp for $10 \mathrm{~min}$. The supernatant $(2 \mu \mathrm{L})$ was injected into the LC-MS system for analysis.

Plasma probe drugs concentration versus time data for each rat was analyzed by DAS software (Version 3.0, Drug Clinical Research Center, Shanghai University of TCM, and Shanghai BioGuider Medicinal Technology Co., Ltd., China). The pharmacokinetic parameters of the test group and control group probe drugs with the $t$-test inspection were 
analyzed by SPSS 18.0 statistical software. A $P<0.05$ was considered as statistically significant.

\section{Results}

3.1. Method Validation. Figure 1 showed the typical chromatograms of a blank plasma sample spiked with probe drugs and IS detected by LC-MS. No interfering endogenous substances were observed at the retention time of the analytes and IS. This demonstrates that the chromatographic separation method has a good peak shape and resolution.

Calibration curves for six probe drugs were generated by linear regression of peak area ratios against concentrations, respectively. The calibration plots of the probe drugs in the range of $10-2000 \mathrm{ng} / \mathrm{mL}$ were listed in Table 1. Each probe drug peak area ratio with concentration has a good linear relationship with the range of concentration. The LLOQ for each probe drug in plasma was $10 \mathrm{ng} / \mathrm{mL}$.

Table 2 showed the results of intraday precision, interday precision, accuracy, extraction recovery, and matrix effect. The relative standard deviation (RSD\%) of the six probe drugs in low, medium, and high, three, concentrations was less than $15 \%$. The intraday and interday accuracy ranged from $88.5 \%$ to $111.2 \%$. The extraction recoveries were ranged from $83.4 \%$ to $94.2 \%$. The results of matrix effect and the percent nominal concentration were more than $85.5 \%$ or less than $111.8 \%$. The results indicate that ion suppression or enhancement from the plasma matrix was negligible for this analytical method.

3.2. Pharmacokinetic Study. The main pharmacokinetic parameters after administration of bupropion, metoprolol, midazolam, phenacetin, omeprazole, and tolbutamide from noncompartment model analysis were summarized in Table 3. In the experiment for acute $\mathrm{H}_{2} \mathrm{~S}$ poisoning and control group, there was a statistically significant difference in the AUC and $C_{\max }$ for bupropion, metoprolol, phenacetin, and tolbutamide $(P<0.05)$, while there was no statistical difference for midazolam and omeprazole $(P>0.05)$.

As can be seen from Table 3 , comparing acute $\mathrm{H}_{2} \mathrm{~S}$ poisoning group with the control group, the pharmacokinetic parameters of bupropion have changed; $t_{1 / 2}$ from the $0.9 \mathrm{~h}$ increased to $1.0 \mathrm{~h}$, but there was no statistical significance $(P>0.05)$; $\mathrm{AUC}_{(0-t)}$ from the 417.3 increased to $650.5 \mathrm{ng} / \mathrm{mL} * \mathrm{~h}$, with significant difference $(P<0.05)$; CL from 27.3 reduced to $16.3 \mathrm{~L} / \mathrm{h} / \mathrm{kg}$, with statistical significance $(P<0.05)$; $C_{\max }$ varied from 276.6 to $411.3 \mathrm{ng} / \mathrm{mL}$, with statistical significance $(P<0.05)$. Comparing acute $\mathrm{H}_{2} \mathrm{~S}$ poisoning group with the control group, the pharmacokinetic parameters of metoprolol have changed; $\mathrm{AUC}_{(0-t)}$ from the 1346.2 increased to $2182.9 \mathrm{ng} / \mathrm{mL} * \mathrm{~h}$, with significant difference $(P<0.01)$; CL from 9.5 reduced to $4.9 \mathrm{~L} / \mathrm{h} / \mathrm{kg}$, with no statistical significance $(P<0.05) ; C_{\max }$ varied from 810.8 to $1235.7 \mathrm{ng} / \mathrm{mL}$, with statistical significance $(P<0.01)$. Comparing acute $\mathrm{H}_{2} \mathrm{~S}$ poisoning group with the control group, the pharmacokinetic parameters of midazolam have almost not changed; $C_{\max }$ varied from 1343.6 to $1353.0 \mathrm{ng} / \mathrm{mL}$, and there no statistical significance $(P>0.05)$. Comparing acute $\mathrm{H}_{2} \mathrm{~S}$ poisoning group with the control group, the pharmacokinetic parameters of phenacetin have changed; $t_{1 / 2}$ from the $0.6 \mathrm{~h}$ reduced to $0.4 \mathrm{~h}$, and there was statistical significance $(P<$ $0.05) ; \mathrm{AUC}_{(0-t)}$ from the 1239.9 increased to $1993.4 \mathrm{ng} / \mathrm{mL} * \mathrm{~h}$ with significant difference $(P<0.05)$; CL from 11.1 reduced to $5.4 \mathrm{~L} / \mathrm{h} / \mathrm{kg}$, but there was no significant difference $(P>$ $0.05) ; C_{\max }$ varied from 1329.2 to $1847.7 \mathrm{ng} / \mathrm{mL}$, and there was significant difference $(P<0.01)$. Comparing acute $\mathrm{H}_{2} \mathrm{~S}$ poisoning group with the control group, the pharmacokinetic parameters of omeprazole have almost not changed; $t_{1 / 2}$ from the $1.1 \mathrm{~h}$ reduced to $0.8 \mathrm{~h}$, and there no statistical significance $(P>0.05)$. Comparing acute $\mathrm{H}_{2} \mathrm{~S}$ poisoning group with the control group, the pharmacokinetic parameters of tolbutamide have changed; $t_{1 / 2}$ from the $3.9 \mathrm{~h}$ increased to $4.2 \mathrm{~h}$, but there was no statistical significance $(P>0.05)$; AUC $_{(0-t)}$ from the 11280.4 increased to $16139.1 \mathrm{ng} / \mathrm{mL} * \mathrm{~h}$, with significant difference $(P<0.05)$; CL from 0.10 reduced to $0.06 \mathrm{~L} / \mathrm{h} / \mathrm{kg}$, and there was statistical significance $(P<$ $0.05)$; $C_{\max }$ varied from 1689.3 to $2216.5 \mathrm{ng} / \mathrm{mL}$, and there was statistical significance $(P<0.05)$.

The representative bupropion, metoprolol, midazolam, phenacetin, omeprazole, and tolbutamide concentration versus time profiles of twelve rats were presented in Figure 2. As could be seen from Figure 2, the AUC and $C_{\max }$ of bupropion, metoprolol, phenacetin, and tolbutamide in acute $\mathrm{H}_{2} \mathrm{~S}$ poisoning group are higher than the control group; this result is consistent with the Table 3 . The concentration-time curve diagram of midazolam and omeprazole in acute $\mathrm{H}_{2} \mathrm{~S}$ poisoning group almost coincided with control group.

\section{Discussion}

Compared to the control group, in acute $\mathrm{H}_{2} \mathrm{~S}$ poisoning group, the AUC bupropion goes higher $(P<0.05)$, CL decreases $(P<0.05)$, and $C_{\max }$ becomes higher $(P<$ $0.05)$; this indicates that acute $\mathrm{H}_{2} \mathrm{~S}$ poisoning will inhibit the activity of CYP2B6 enzyme. Similar results were found for tolbutamide; the $\mathrm{AUC}_{(0-t)}$ increased $(P<0.05)$; $\mathrm{CL}$ reduced $(P<0.05)$; $C_{\max }$ became higher $(P<0.05)$; this indicates that acute $\mathrm{H}_{2} \mathrm{~S}$ poisoning will inhibit the activity of CYP2C9 enzyme.

Compared to the control group, in the acute $\mathrm{H}_{2} \mathrm{~S}$ poisoning group, the $\mathrm{AUC}_{(0-t)}$ of metoprolol increased $(P<0.01)$; $C_{\max }$ became higher $(P<0.01)$; this indicates that acute $\mathrm{H}_{2} \mathrm{~S}$ poisoning will inhibit the activity of CYP2D6 enzyme. Similar results were found for phenacetin; $\mathrm{AUC}_{(0-t)}$ increased $(P<0.05)$; $C_{\max }$ became higher $(P<0.01)$; this indicates that acute $\mathrm{H}_{2} \mathrm{~S}$ poisoning will inhibit the activity of CYP1A2 enzyme.

Compared to the control group, in the acute $\mathrm{H}_{2} \mathrm{~S}$ poisoning group, the pharmacokinetic parameters of midazolam have almost not changed; this indicates that the acute $\mathrm{H}_{2} \mathrm{~S}$ poisoning will not induce or inhibit the activity of CYP3A4 enzyme. Similar results were found for omeprazole; the pharmacokinetic parameters of omeprazole have almost not changed between control group and acute $\mathrm{H}_{2} \mathrm{~S}$ poisoning group; this shows that the acute $\mathrm{H}_{2} \mathrm{~S}$ poisoning will not induce or inhibit the activity of CYP2C19 enzyme.

The results demonstrated that acute $\mathrm{H}_{2} \mathrm{~S}$ poisoning could inhibit the activity of CYP2B6, CYP2D6, CYP1A2, and CYP2C9 of rats. The results may make sense for the clinical 


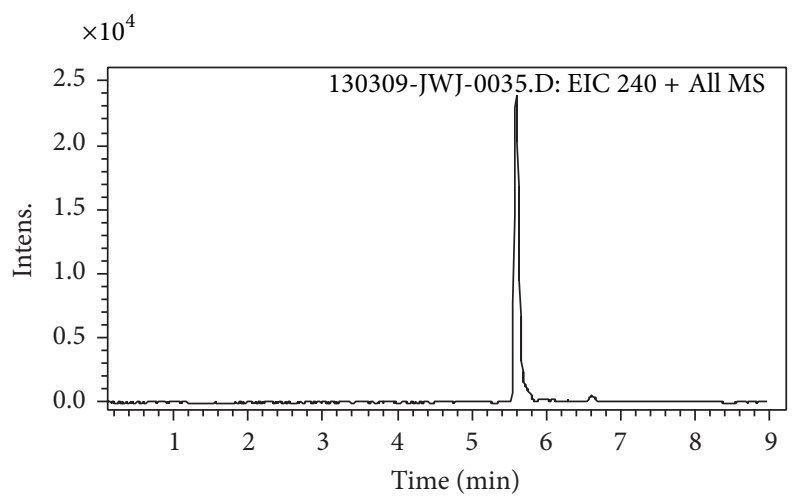

(a)

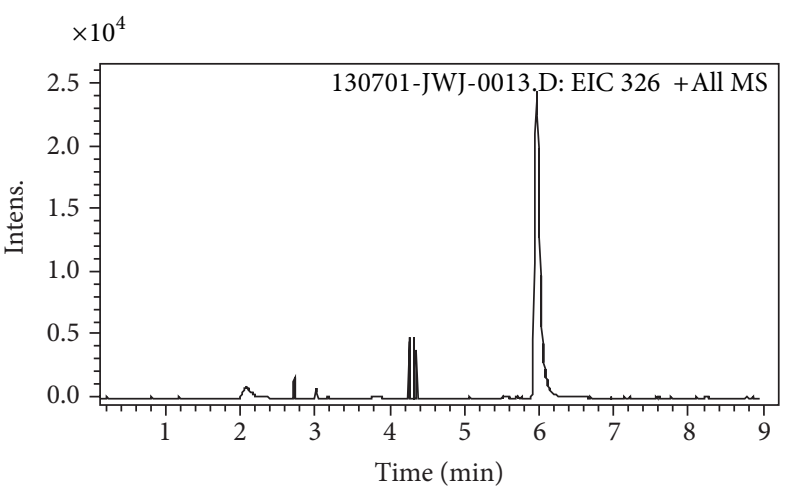

(c)

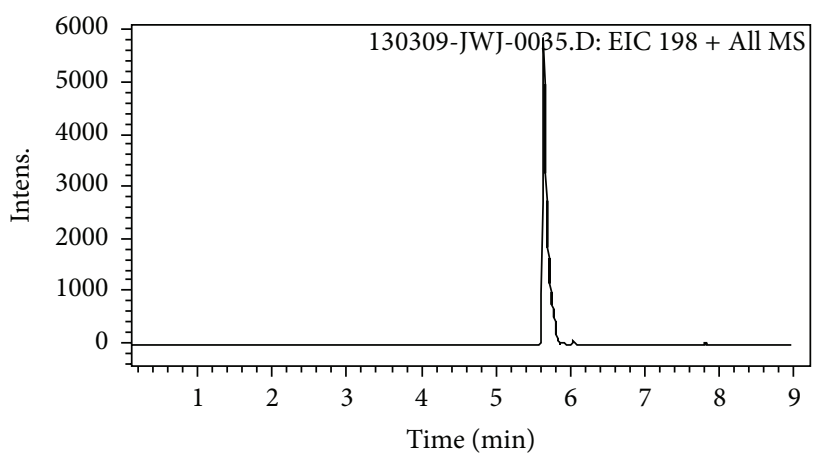

(e)

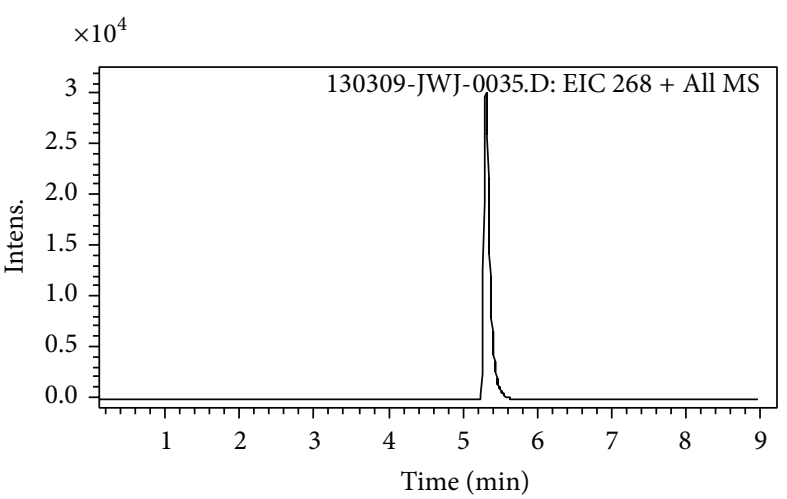

(b)

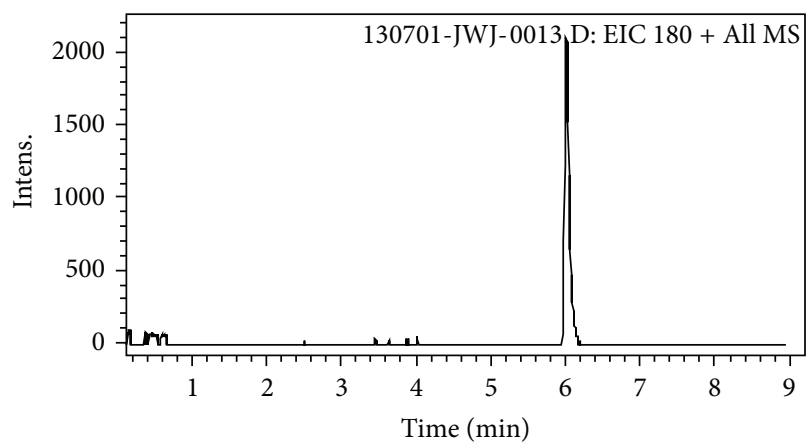

(d)

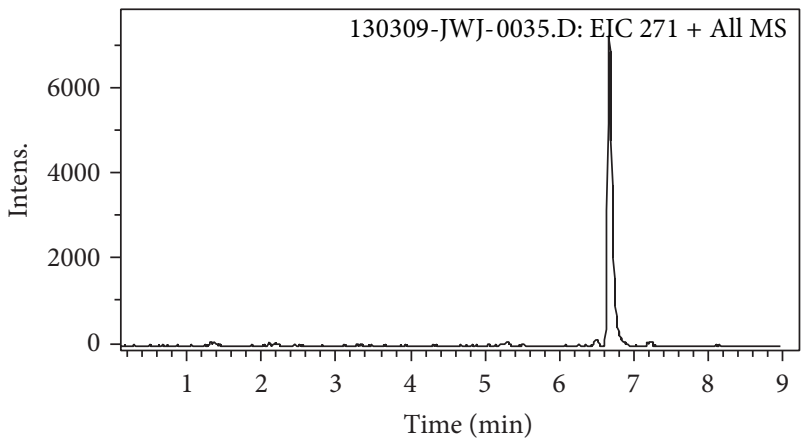

(f)

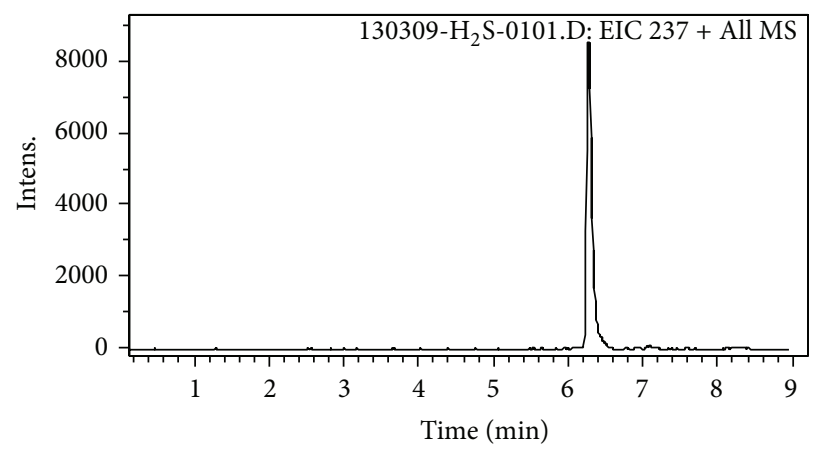

(g)

FIGURE 1: LC-MS chromatograms: blank plasma spiked with bupropion (1), metoprolol (2), midazolam (3), phenacetin (4), omeprazole (5), tolbutamide (6), and carbamazepine (IS) (7). 


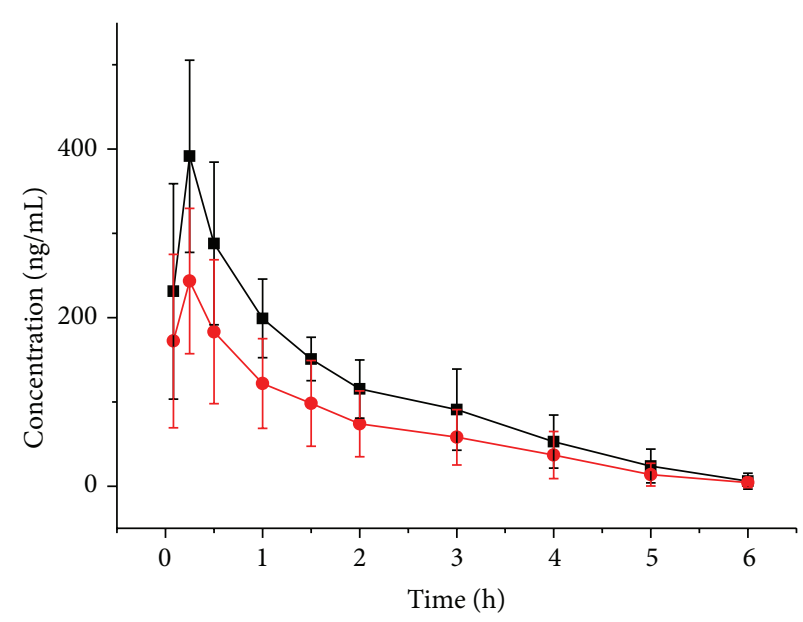

(a)

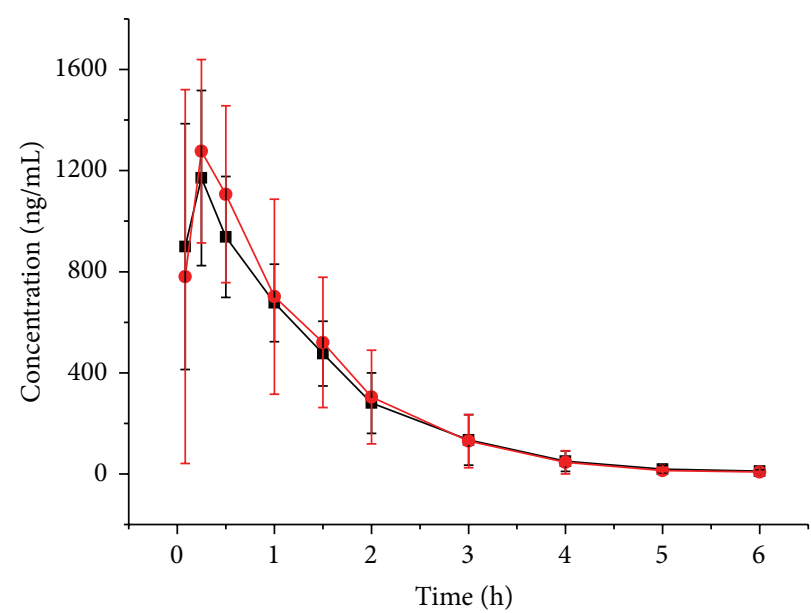

(c)

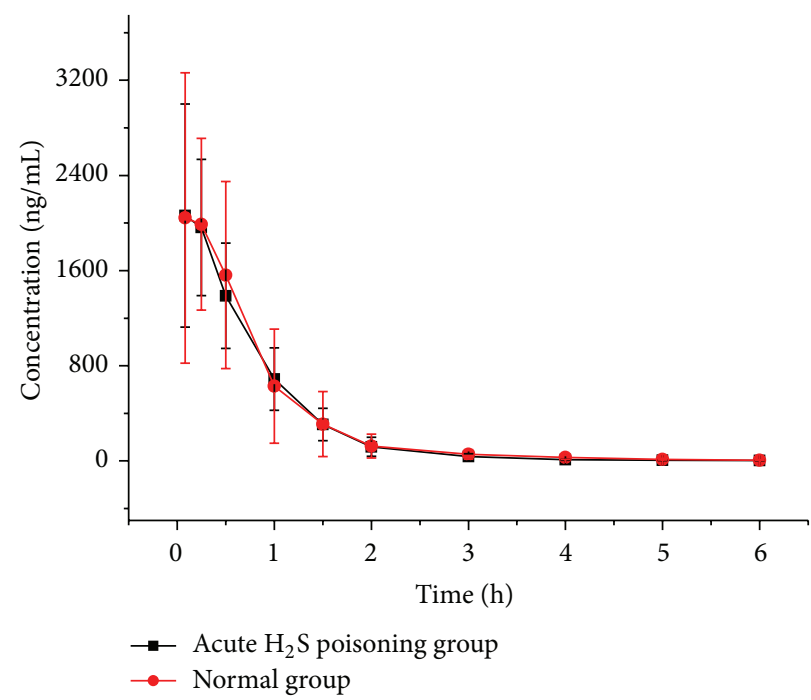

(e)

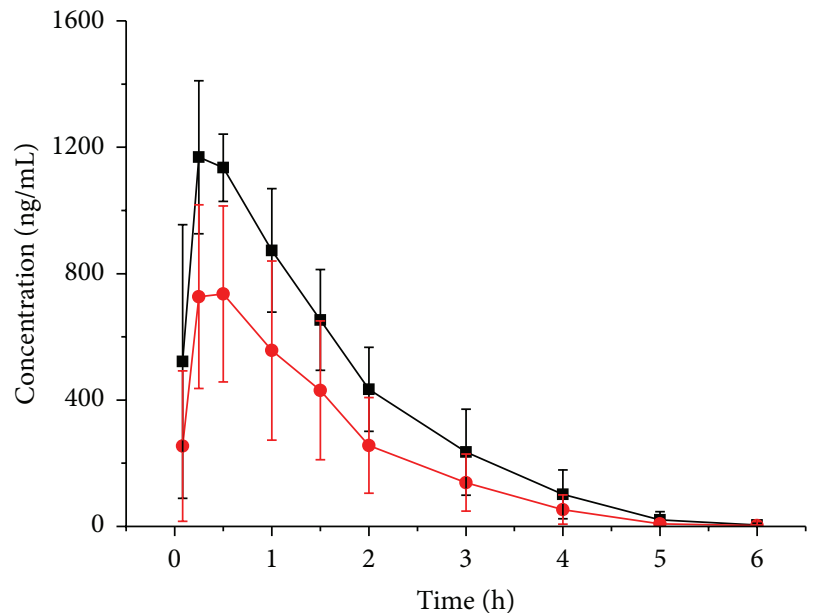

(b)

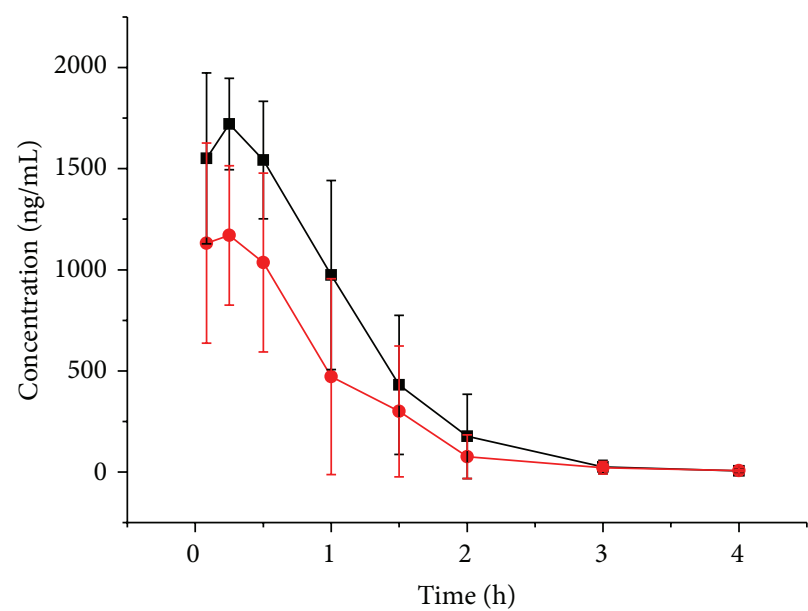

(d)

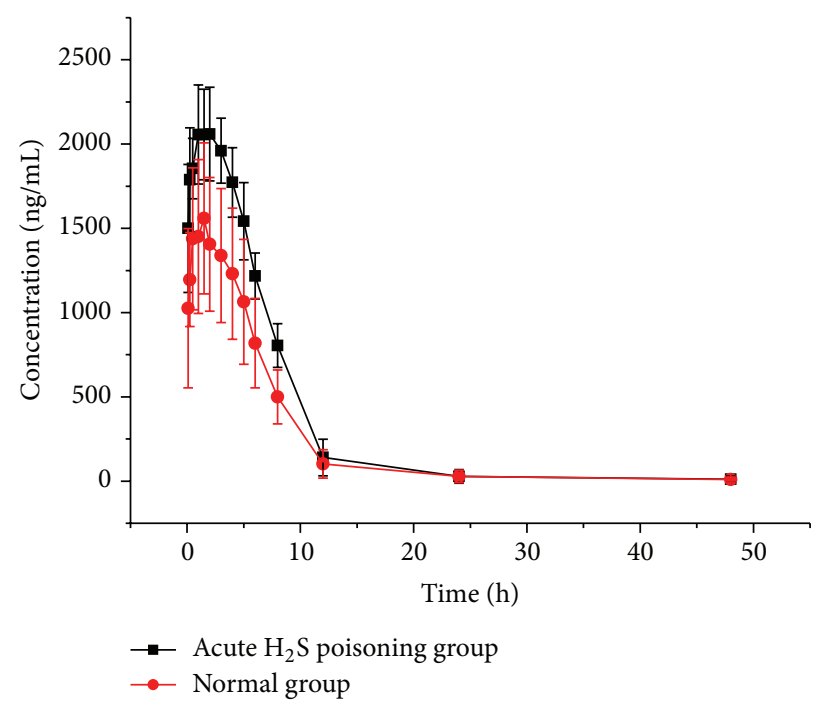

(f)

Figure 2: The pharmacokinetics profiles of bupropion (a), metoprolol (b), midazolam (c), phenacetin (d), omeprazole (e), and tolbutamide (f) after oral administration in acute hydrogen sulfide poisoning group and control group rats $(n=8)$. 
TABLE 1: Regression equation and correlation coefficient for six probe drugs.

\begin{tabular}{lccc}
\hline Probe drugs & Liner range $(\mathrm{ng} / \mathrm{mL})$ & Regression equation & Correlation coefficient \\
\hline Bupropion & $10-2000$ & $y=0.002629 x+0.055076$ & 0.997233 \\
Metoprolol & $10-2000$ & $y=0.003557 x+0.110593$ & 0.997110 \\
Midazolam & $10-2000$ & $y=0.003584 x+0.146928$ & 0.996311 \\
Phenacetin & $10-2000$ & $y=0.000656 x-0.001949$ & 0.998495 \\
Omeprazole & $10-2000$ & $y=0.000602 x+0.032108$ & 0.996069 \\
Tolbutamide & $10-2000$ & $y=0.000576 x+0.012733$ & 0.995463 \\
\hline
\end{tabular}

$y$ : peak area ratio of probe drugs versus IS; $x$ : concentration of probe drugs.

TABLE 2: Precision, accuracy, recovery, and matrix effect of six probe drugs in rat plasma (mean $\pm \mathrm{SD}, n=6)$.

\begin{tabular}{|c|c|c|c|c|c|c|c|}
\hline \multirow{2}{*}{ Compound } & \multirow{2}{*}{ Concentration $(\mathrm{ng} / \mathrm{mL})$} & \multicolumn{2}{|c|}{ Precision RSD (\%) } & \multicolumn{2}{|c|}{ Accuracy (\%) } & \multirow{2}{*}{ Recovery } & \multirow{2}{*}{ Matrix effect } \\
\hline & & Intraday & Interday & Intraday & Interday & & \\
\hline \multirow{3}{*}{ Bupropion } & 20 & 6.7 & 9.1 & 102.6 & 102.8 & $83.4 \pm 5.1$ & $111.8 \pm 4.7$ \\
\hline & 200 & 3.2 & 7.6 & 101.7 & 94.6 & $87.4 \pm 4.9$ & $101.2 \pm 4.8$ \\
\hline & 1600 & 2.6 & 9.3 & 97.6 & 106.8 & $91.5 \pm 4.7$ & $96.4 \pm 3.3$ \\
\hline \multirow{3}{*}{ Metoprolol } & 20 & 13.3 & 13.4 & 104.5 & 94.8 & $84.9 \pm 6.9$ & $109.1 \pm 4.7$ \\
\hline & 200 & 5.4 & 9.3 & 93.8 & 95.9 & $87.5 \pm 5.8$ & $106.3 \pm 3.9$ \\
\hline & 1600 & 6.4 & 6.9 & 93.1 & 103.6 & $90.1 \pm 4.4$ & $97.2 \pm 3.8$ \\
\hline \multirow{3}{*}{ Midazolam } & 20 & 7 & 9.4 & 103.4 & 109.9 & $90.3 \pm 7.5$ & $104.3 \pm 4.9$ \\
\hline & 200 & 6.6 & 5.9 & 92.3 & 88.7 & $92.1 \pm 6.8$ & $102.4 \pm 5.5$ \\
\hline & 1600 & 2.6 & 6.5 & 96.2 & 106.3 & $94.2 \pm 5.6$ & $99.1 \pm 4.8$ \\
\hline \multirow{3}{*}{ Phenacetin } & 20 & 6.3 & 8.6 & 109.5 & 111.2 & $88.6 \pm 5.7$ & $88.2 \pm 6.2$ \\
\hline & 200 & 11.6 & 10.2 & 105.7 & 96.3 & $86.6 \pm 7.3$ & $90.5 \pm 6.8$ \\
\hline & 1600 & 3.4 & 7.6 & 97.8 & 105.2 & $92.6 \pm 4.3$ & $87.4 \pm 4.2$ \\
\hline \multirow{3}{*}{ Omeprazole } & 20 & 12.8 & 14.8 & 88.5 & 98.7 & $93.1 \pm 9.2$ & $86.7 \pm 6.4$ \\
\hline & 200 & 5 & 7.7 & 91.7 & 104.5 & $88.7 \pm 5.6$ & $89.5 \pm 4.7$ \\
\hline & 1600 & 4.9 & 8.6 & 94.5 & 105.1 & $90.2 \pm 7.1$ & $85.5 \pm 6.7$ \\
\hline \multirow{3}{*}{ Tolbutamide } & 20 & 11.4 & 13.5 & 91.8 & 103.4 & $89.1 \pm 7.8$ & $90.1 \pm 4.8$ \\
\hline & 200 & 3.5 & 6 & 100.8 & 90.7 & $93.8 \pm 5.6$ & $87.5 \pm 7.1$ \\
\hline & 1600 & 6.1 & 7.2 & 105.3 & 93.6 & $94.1 \pm 4.7$ & $85.3 \pm 6.5$ \\
\hline
\end{tabular}

oral use of drugs for the people after acute $\mathrm{H}_{2} \mathrm{~S}$ poisoning. Drugs are metabolized by CYP2B6, CYP2D6, CYP1A2, and CYP2C9 enzymes after acute H2S poisoning; we should pay close attention to changes in the plasma concentration to avoid drug interactions that may occur.

\section{Conclusion}

The concentrations of probe drugs in rat plasma were successfully measured by LC-MS. In the experiment for acute $\mathrm{H}_{2} \mathrm{~S}$ poisoning and control group, there was a statistically significant increase in the AUC and $C_{\max }$ for bupropion, metoprolol, phenacetin, and tolbutamide, while there was no statistical pharmacokinetics difference for midazolam and omeprazole. Acute $\mathrm{H}_{2} \mathrm{~S}$ poisoning could inhibit the activity of
CYP2B6, CYP2D6, CYP1A2, and CYP2C9 of rats. The results may make sense for the clinical oral use of drugs for the people after acute $\mathrm{H}_{2} \mathrm{~S}$ poisoning.

\section{Conflict of Interests}

The authors declare that there is no conflict of interests regarding the publication of this paper.

\section{Acknowledgments}

This study was supported by Grants from the National Natural Science Foundation of China, no. 81102297; the Science and Technology Committee of Shanghai Municipality, China, no. KF1101; the Youth Talent Program Foundation of The 


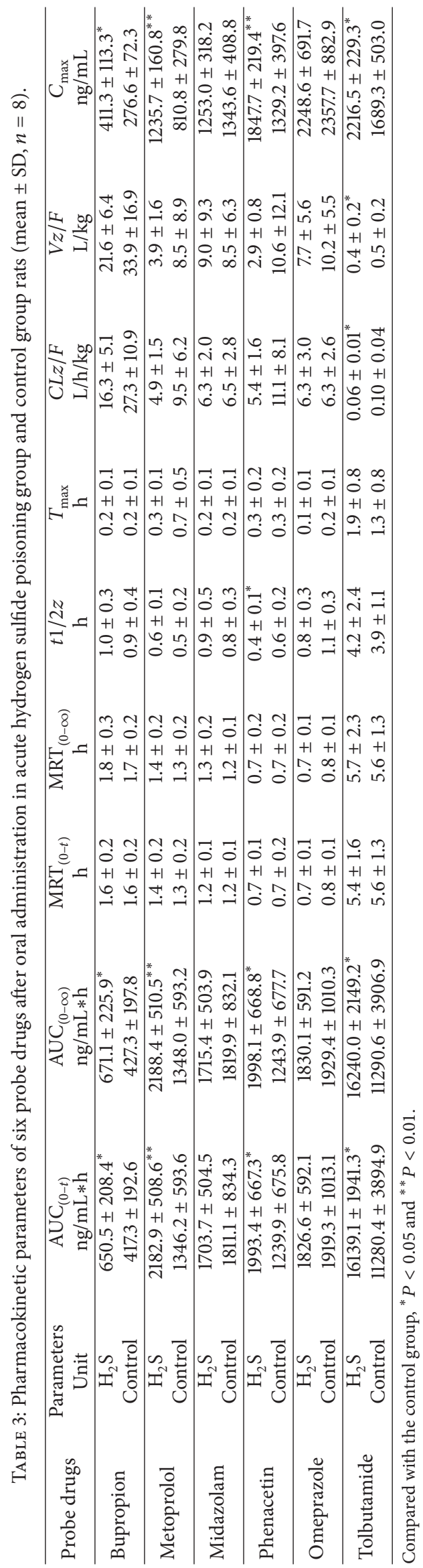


First Affiliated Hospital of Wenzhou Medical University (qnyc010).

\section{References}

[1] K. Maebashi, K. Iwadate, K. Sakai et al., "Toxicological analysis of 17 autopsy cases of hydrogen sulfide poisoning resulting from the inhalation of intentionally generated hydrogen sulfide gas," Forensic Science International, vol. 207, no. 1-3, pp. 91-95, 2011.

[2] B. Nam, H. Kim, Y. Choi et al., "Neurologic sequela of hydrogen sulfide poisoning," Industrial Health, vol. 42, no. 1, pp. 83-87, 2004.

[3] R. J. Reiffenstein, W. C. Hulbert, and S. H. Roth, "Toxicology of hydrogen sulfide," Annual Review of Pharmacology and Toxicology, vol. 32, pp. 109-134, 1992.

[4] T. L. Guidotti, "Hydrogen sulphide," Occupational Medicine, vol. 46, no. 5, pp. 367-371, 1996.

[5] S. Tanaka, S. Fujimoto, Y. Tamagaki, K. Wakayama, K. Shimada, and J. Yoshikawa, "Bronchial injury and pulmonary edema caused by hydrogen sulfide poisoning," American Journal of Emergency Medicine, vol. 17, no. 4, pp. 427-429, 1999.

[6] D. S. Gabbay, F. De Roos, and J. Perrone, "Twenty-foot fall averts fatality from massive hydrogen sulfide exposure," Journal of Emergency Medicine, vol. 20, no. 2, pp. 141-144, 2001.

[7] J. W. Snyder, E. F. Safir, G. P. Summerville, and R. A. Middleberg, "Occupational fatality and persistent neurological sequelae after mass exposure to hydrogen sulfide," American Journal of Emergency Medicine, vol. 13, no. 2, pp. 199-203, 1995.

[8] S. Kage, K. Takekawa, K. Kurosaki, T. Imamura, and K. Kudo, "The usefulness of thiosulfate as an indicator of hydrogen sulfide poisoning: Three cases," International Journal of Legal Medicine, vol. 110, no. 4, pp. 220-222, 1997.

[9] S. Kage, H. Ikeda, N. Ikeda, A. Tsujita, and K. Kudo, "Fatal hydrogen sulfide poisoning at a dye works," Legal Medicine, vol. 6, no. 3, pp. 182-186, 2004.

[10] L. D. Knight and S. E. Presnell, "Death by sewer gas: case report of a double fatality and review of the literature," American Journal of Forensic Medicine and Pathology, vol. 26, no. 2, pp. 181-185, 2005.

[11] S. Kage, T. Nagata, and K. Kudo, "Determination of thiosulfate in body fluids by GC and GC/MS," Journal of Analytical Toxicology, vol. 15, no. 3, pp. 148-150, 1991.

[12] T. Nagata, S. Kage, K. Kimura, K. Kudo, and T. Imamura, "How to diagnose polysulphide poisoning from tissue samples," International Journal of Legal Medicine, vol. 106, no. 6, pp. 288-290, 1994.

[13] M. Ago, K. Ago, and M. Ogata, "Two fatalities by hydrogen sulfide poisoning: variation of pathological and toxicological findings," Legal Medicine, vol. 10, no. 3, pp. 148-152, 2008.

[14] T. H. MILBY, "Hydrogen sulfide intoxication. Review of the literature and report of unusual accident resulting in two cases of nonfatal poisoning," Journal of Occupational Medicine, vol. 4, pp. 431-437, 1962.

[15] T. L. Guidotti, "Occupational exposure to hydrogen sulfide in the sour gas industry: some unresolved issues," International Archives of Occupational and Environmental Health, vol. 66, no. 3, pp. 153-160, 1994.

[16] I. G. Denisov, T. M. Makris, S. G. Sligar, and I. Schlichting, "Structure and chemistry of cytochrome P450," Chemical Reviews, vol. 105, no. 6, pp. 2253-2277, 2005.
[17] J. Rittle and M. T. Green, "Cytochrome P450 compound I: capture, characterization, and C-H bond activation kinetics," Science, vol. 330, no. 6006, pp. 933-937, 2010.

[18] D. F. V. Lewis, "Human cytochromes P450 associated with phase 1 metabolism of drugs and other xenobiotics: a compilation of substrates and inhibitors of the CYP1, CYP2 and CYP3 families," Current Medicinal Chemistry, vol. 10, no. 19, pp. 1955-1972, 2003.

[19] O. Pelkonen, "Human CYPs: in vivo and clinical aspects," Drug Metabolism Reviews, vol. 34, no. 1-2, pp. 37-46, 2002.

[20] H. Nishimuta, T. Nakagawa, N. Nomura, and M. Yabuki, "Species differences in hepatic and intestinal metabolic activities for 43 human cytochrome $\mathrm{P} 450$ substrates between humans and rats or dogs," Xenobiotica, vol. 43, no. 11, pp. 948-955, 2013.

[21] F. Montastruc, A. Sommet, E. Bondon-Guitton et al., "The importance of drug-drug interactions as a cause of adverse drug reactions: a pharmacovigilance study of serotoninergic reuptake inhibitors in France," European Journal of Clinical Pharmacology, vol. 69, no. 4, pp. 885-888, 2013.

[22] G. R. Wilkinson, "Drug therapy: drug metabolism and variability among patients in drug response," The New England Journal of Medicine, vol. 352, no. 21, pp. 2211-2259, 2005.

[23] S. Turpault, W. Brian, R. Van Horn et al., "Pharmacokinetic assessment of a five-probe cocktail for CYPs 1A2, 2C9, 2C19, 2D6 and 3A," British Journal of Clinical Pharmacology, vol. 68, no. 6, pp. 928-935, 2009.

[24] O. Q. P. Yin, S. S. L. Lam, C. M. Y. Lo, and M. S. S. Chow, "Rapid determination of five probe drugs and their metabolites in human plasma and urine by liquid chromatography/tandem mass spectrometry: application to cytochrome P450 phenotyping studies," Rapid Communications in Mass Spectrometry, vol. 18, no. 23, pp. 2921-2933, 2004.

[25] K. Kozakai, Y. Yamada, M. Oshikata et al., "Reliable highthroughput method for inhibition assay of 8 cytochrome P450 isoforms using cocktail of probe substrates and stable isotopelabeled internal standards," Drug Metabolism and Pharmacokinetics, vol. 27, pp. 520-529, 2012.

[26] C.-F. Zhou and X.-Q. Tang, "Hydrogen sulfide and nervous system regulation," Chinese Medical Journal, vol. 124, no. 21, pp. 3576-3582, 2011.

[27] K. H. Kilburn, J. D. Thrasher, and M. R. Gray, "Low-level hydrogen sulfide and central nervous system dysfunction," Toxicology and Industrial Health, vol. 26, no. 7, pp. 387-405, 2010.

[28] B. H. Tan, P. T.-H. Wong, and J.-S. Bian, "Hydrogen sulfide: a novel signaling molecule in the central nervous system," Neurochemistry International, vol. 56, no. 1, pp. 3-10, 2010.

[29] Y. H. Liu, M. Lu, L. F. Hu, P. T. Wong, G. D. Webb, and J. S. Bian, "Hydrogen sulfide in the mammalian cardiovascular system," Antioxidants \& Redox Signaling, vol. 17, pp. 141-185, 2012.

[30] K. R. Olson and N. L. Whitfield, "Hydrogen sulfide and oxygen sensing in the cardiovascular system," Antioxidants and Redox Signaling, vol. 12, no. 10, pp. 1219-1234, 2010.

[31] R. J. Pearson, T. Wilson, and R. Wang, "Endogenous hydrogen sulfide and the cardiovascular system-what's the smell all about?" Clinical and Investigative Medicine, vol. 29, no. 3, pp. 146-150, 2006.

[32] V. Dixit, N. Hariparsad, P. Desai, and J. D. Unadkat, "In vitro LCMS cocktail assays to simultaneously determine human cytochrome P450 activities," Biopharmaceutics and Drug Disposition, vol. 28, no. 5, pp. 257-262, 2007. 

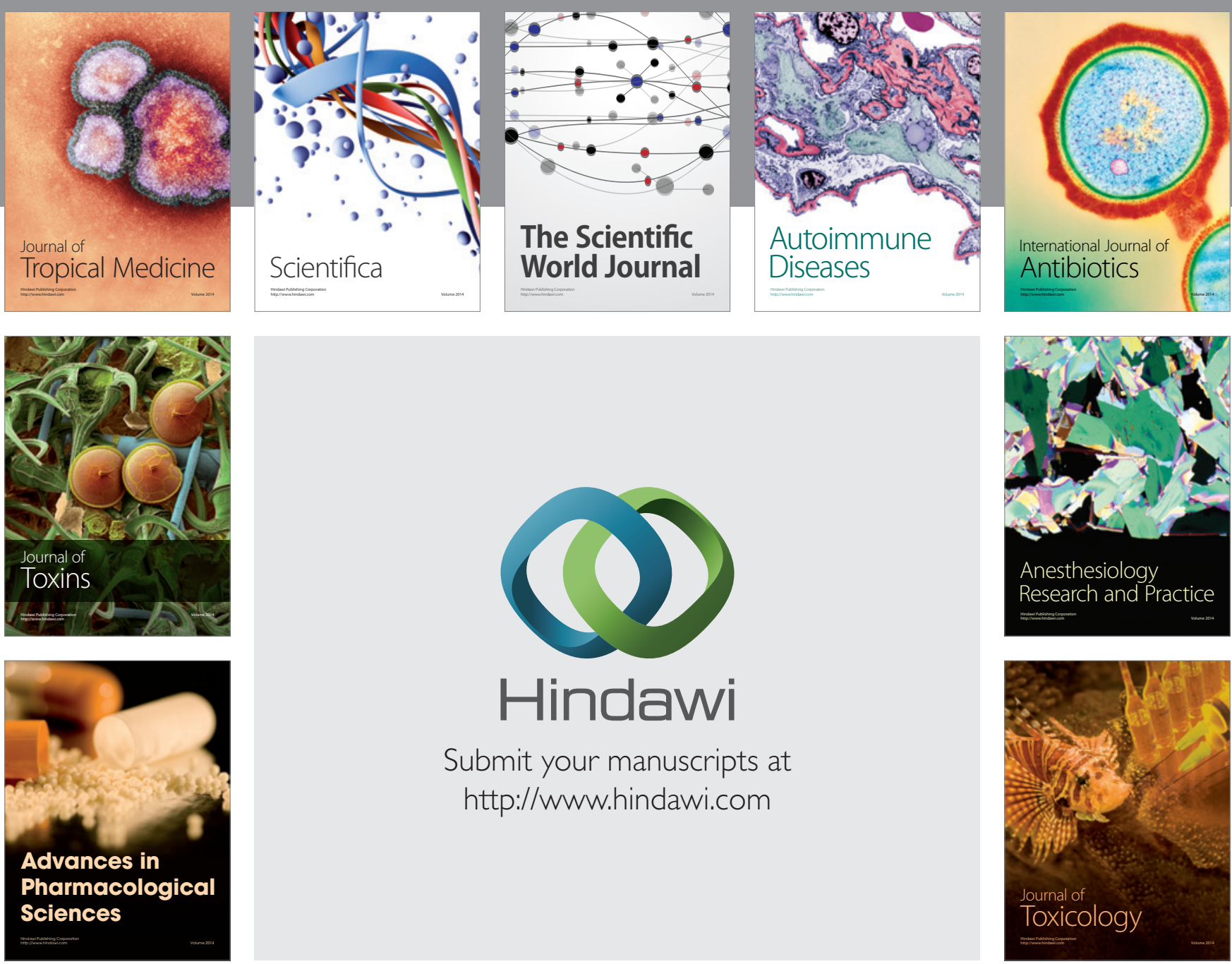

\section{Hindawi}

Submit your manuscripts at

http://www.hindawi.com
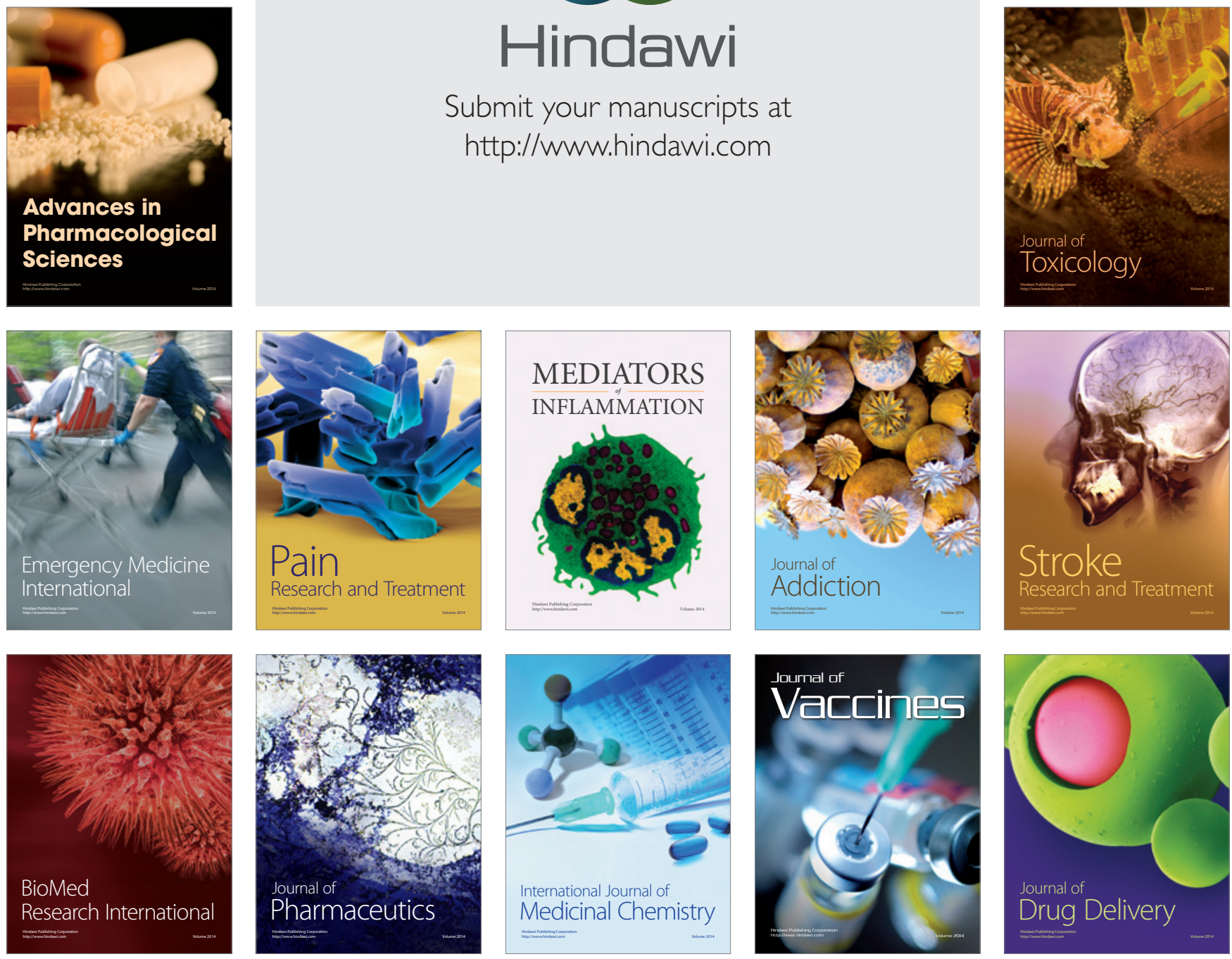